\title{
Production, Prices, and Money in Four Industrial Countries
}

T HERE has been a curious and, from the point of view of the affected countries, an unfortunate uniformity in the economic performance of the major industrial countries of the world over the last few years. These countries have experienced the coincidence of simultaneously accelerating prices and rising unemployment. Starting in late 1970 or early 1971 , many of the major industrial countries of the world experienced a uniform slowdown in output, with its adverse effects on the level of unemployment. At the same time, inflation in these countries had generally accelerated. The word "stagflation" has been coined to describe this state of affairs. Fortunately, most of these countries have experienced a recovery in real output growth in the first half of 1972.

\section{Emergence of Stagflation}

Real output growth in four of the largest industrial countries (which are also important trading partners of the United States) is illustrated in the chart on p. 14 of this article. For each country (France, Germany, Japan, and the United Kingdom) industrial production exhibited little or no growth in the yearand-a-half ending December 1971. Even the remarkable Japanese economy's growth of industrial output was under 5 percent during this period, in contrast to its more typical post-war growth rate in excess of 15 percent.

While output and employment were stagnant or growing at sharply reduced rates, inflation in these countries had gradually accelerated. In most of the countries, inflation was significantly higher in the last two to three years than in previous years when the rate of growth in output was much closer to capacity levels. Thus, not only did these countries suffer from stagnant output and rising prices, but previously when output was growing close to capacity rates, price increases were actually less.

\section{Alternative Explanations of Stagflation}

What explains this state of affairs? Some commentators have alleged that the classical laws of economics no longer apply in an affluent and alienated society; we have entered an era of permanent inflation relating to a breakdown in the ordering of society. This is reflected in the excessive wage demands of labor, irrespective of the consequences for output and the employment opportunities of recent entrants into the labor force. This pessimistic view of events would assert that we are observing the economic consequences of a basically social phenomenon.

There is an economic explanation, however, which is consistent with the observed facts. This economic explanation, almost classical in its simplicity, has recently been restated and strengthened based on U.S. experience. This approach rests on two propositions about economic relationships: (1) the long-run rate of growth in the money stock is a major determinant of the long-run rate of inflation; (2) fluctuations in the rate of growth of money will, in the short run, lead to similar fluctuations in the growth of real output. In other words, monetary influences, as measured by rates of change in the money stock, have a major impact in the short run on the level of real economic activity, and in the long run on the rate of inflation.

Evidence on the central role of monetary influences on economic activity is supported not only by U.S. data, but also by data from other industrial countries, including those countries considered in this note. It is not our purpose to reproduce the detailed theoretical structure and empirical evidence which has been de- 


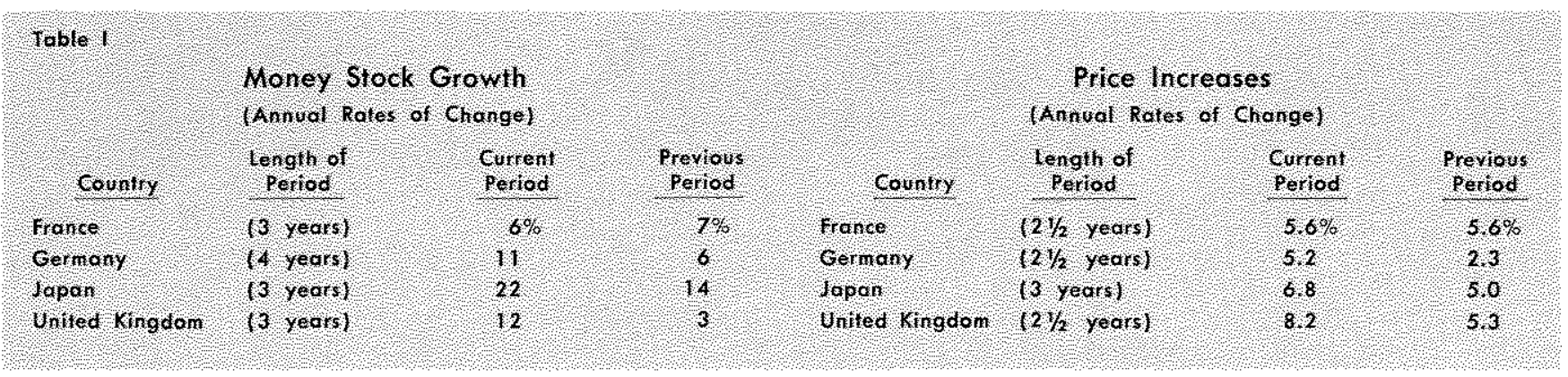

veloped to support these propositions. Such support can be found elsewhere, including previous issues of this Review.

The evidence considered here is presented in the form of charts and tables rather than with the use of more formal and sophisticated statistical procedures. As such, it is limited to comparing the relationships between money and prices, and money and output, without consideration of the important initial conditions in each country which can affect both the time lag and the magnitude of the relationship. In spite of the simplicity of the procedure, the results are strongly suggestive of the validity of the propositions.

\section{Money and Prices}

We will first consider the relation between money and prices. Table $I$ shows the average annual rate of growth in the money stock for the four countries through the first half of 1972 . With the exception of France, the average growth rate in the money supply in the last three or four years has been at a signifcantly higher rate than in the previous time period of equal length. ${ }^{2}$

The table also shows for each country the average inflation rate in the current two- to three-year period versus the previous time period of the same length. Except for France, each country has experienced a significant acceleration in inflation.

In each country the changes in inflation have been in the same direction as changes in the growth of

${ }^{1}$ See Leonall C. Andersen and Jerry L. Jordan, "Monetary and Fiscal Actions: A Test of Their Relative Importance in Economic Stabilization," this Review (November 1968); Milton Friedman and Anna Schwartz, "A Monetary History of the United States 1867-1960" (Princeton, New Jersey; Princeton University Press, 1963), and Monetary Trends in the U.S. and the U.K. (a forthcoming NBER Occasional Paper), chap. 2; Michael W. Keran, "Monetary and Fiscal Influences on Economic Activity - The Foreign Experience," this Review (February 1970); and "Selecting a Monetary Indicator - Evidence from the United States and Other Developed Countries," this Review (September 1970).

2 Each period was chosen on the basis of a significant change in the growth of money. money. In three countries (Germany, Japan and the United Kingdom) the trend growth rates in money and prices have increased substantially. In one country (France) the trend growth rates in money and prices have remained substantially unchanged between the two periods; the trend growth of money declined slightly while prices increased at a constant 5.6 percent rate. However, this is as strong a confirmation of the relation between money and prices as when the trend growth in money is significantly changed. When the trend growth in money remains stable over time, the trend growth in prices exhibits a very similar pattern.

The relation shown in the table is consistent with the view that the effects of a change in money on prices is distributed over a period of time. The nature of the lag depends upon the unique economic conditions in each country - the history of past inflation, the amount of excess capacity, and the degree and forms of competition in the labor and commodity markets.

Given this uncertainty about the length of the lags, the most that can be said is that a change in the trend growth of money in the last three to four years can be associated with a change in the trend growth of prices in the last two to three years. Because of differences in economic and social structures in each country, the exact length of the time lag between money and prices can be different for each country.

As the link between money and prices is postulated to hold mainly in the long run, one should observe an even clearer relationship with longer time periods than those used in Table 1. To confirm this, the relationship between money and prices was compared for the period from the early 1950 s to 1970 for all the countries in this Bank's "Ten Industrial Countries" release. $^{3}$

For each country two time periods are reported. The periods were determined on the basis of signifi-

3Data are drawn from "Rates of Change in Economic Data for Ten Industrial Countries" (Annual Data 1952-71), issued by this Bank (August 1972). 


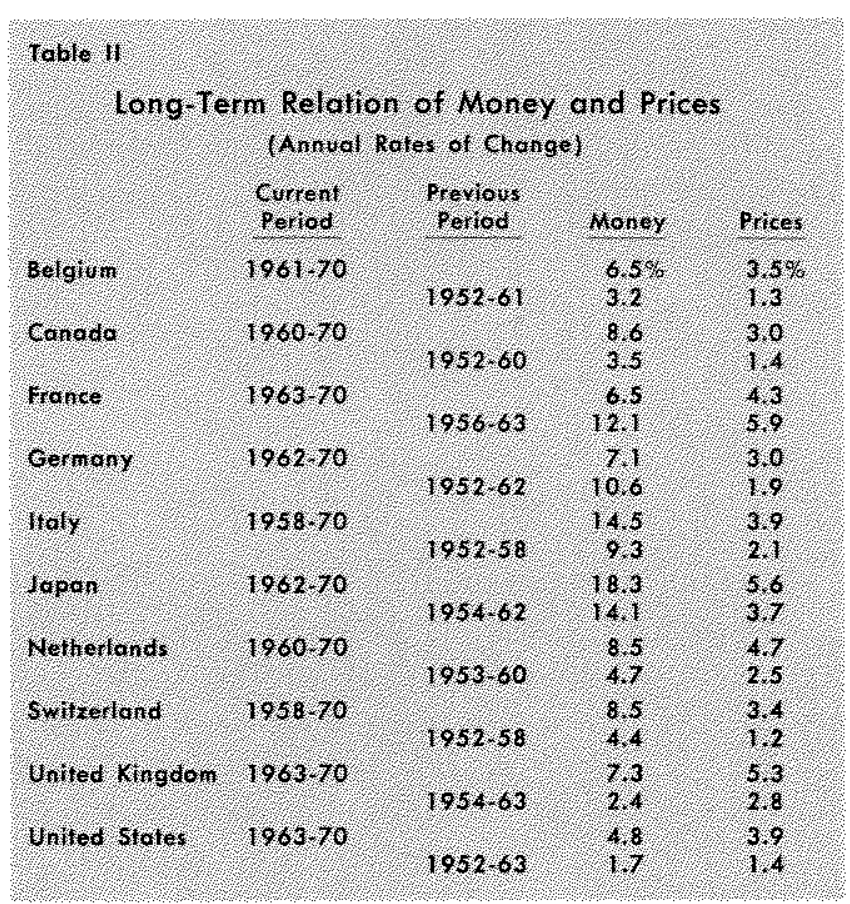

cantly different growth rates in the money stock. The years included in the two time periods are listed in the first two columns of Table II, and the growth rates in the money stock are listed in the third column. The corresponding rates of change in prices are listed in the fourth column. In order to take into account, at least roughly, the lag relationship between money and prices, the price data are in each case lagged one year with respect to the money data. For example, in the case of Belgium, the current period is 1961-70, when the money stock grew at a 6.5 percent annual rate. The corresponding annual rise in prices of 3.5 percent is from 1962-71.

Of the ten countries considered, eight countries had an acceleration in the growth of the money stock in the current period relative to the previous period. In all eight countries, there was a corresponding increase in inflation. In two countries, France and Germany, the growth in the money stock decelerated in the current period relative to the previous period. In the case of France, inflation also decreased. However, in the case of Germany, inflation increased in the current period relative to the previous period. Thus in nine of the ten countries the rate of change in prices was in the same direction as the rate of change in money.

The German exception can be explained on the basis of an unusual change in the economic setting in Germany between the 1950s and 1960s. An implicit assumption behind the long-term relation of money and prices is that the capacity of the economy to produce real goods and services grows at a relatively fixed trend rate determined by the rate of growth in labor, capital, and technology. If the change in the growth of the money supply occurred at a time when there was a change in the growth trend of the economy, then the normal relationship between money and prices would be obscured.

Germany, it seems, did experience such a change in the growth of its capacity. Until 1961, the real growth in the German economy was augmented by the availability of skilled labor from East Germany. When this was curtailed by the erection of the Berlin Wall, the real growth potential of the German economy declined from an average of about 8.5 percent per year to 5.5 percent per year. ${ }^{4}$ Because the decline in the growth of the money stock in Germany paralleled the decline in the growth capacity, the effect of money on prices was blurred in this particular case.

It is interesting to note that the comparisons of Germany in Table $I$, all of which are drawn from the period since 1961, support the positive relationship between money and prices which has been observed in other industrial countries.

\section{Money and Output}

The second proposition concerns the short-term relationship between changes in money and changes in real output. This short-term relationship will necessarily be less predictable than the long-term relationship between money and prices. The reason is that there are more nonmonetary influences on real output than there are on prices. Such obvious ones as strikes and national disasters can have a major effect on the growth in real output in the short run, even to the point of obscuring what would otherwise be a close relationship to changes in money.

More fundamentally, the long-term rate of growth in real output is determined by the rate of growth of labor, capital, and technology. If the economy is already growing at capacity, a short-term acceleration in money is unlikely to call forth much additional growth in real output.

Due to the importance of nonmonetary factors in influencing the short-run growth of real output, only during periods of clear cyclical movements in money can we expect to find a close, corresponding movement in real output. The most illuminating aspect of the recent monetary experience in the four countries con-

4The loss of East German labor was only partially compensated for by the increased hiring of anskilled labor from other countries. 


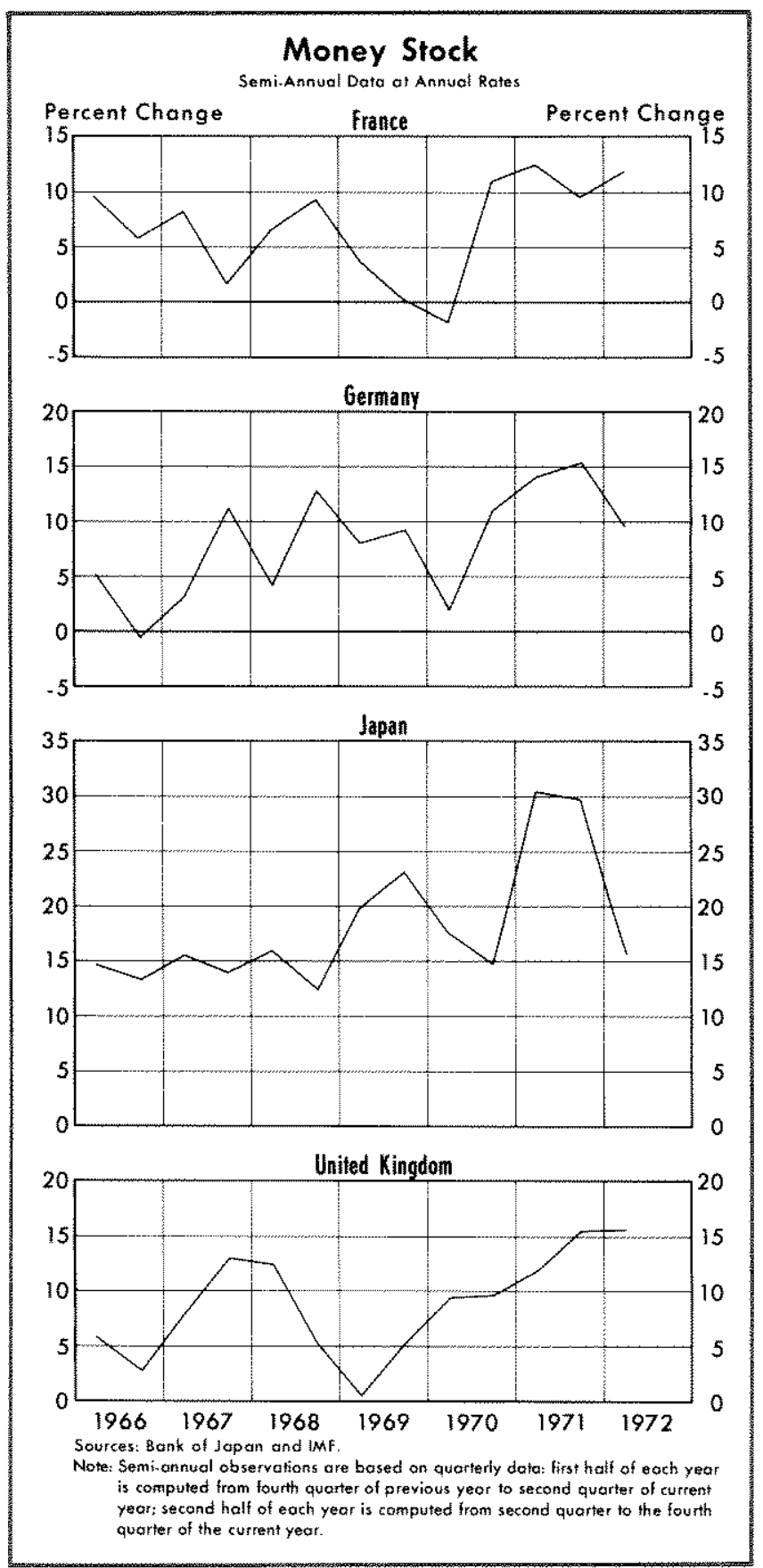

sidered is that there has in fact been a clear cyclical pattern in the growth of money. In the last four years money has first decelerated and then accelerated in all four countries. This is clearly illustrated in the chart entitled "Money Stock," where the half-year growth rates in money for France, Germany, Japan, and the United Kingdom are shown.

The effects of cyclical movements in money on real output are illustrated in the chart entitled "Real Output." For each country (except France) there are two measures of real output-industrial production

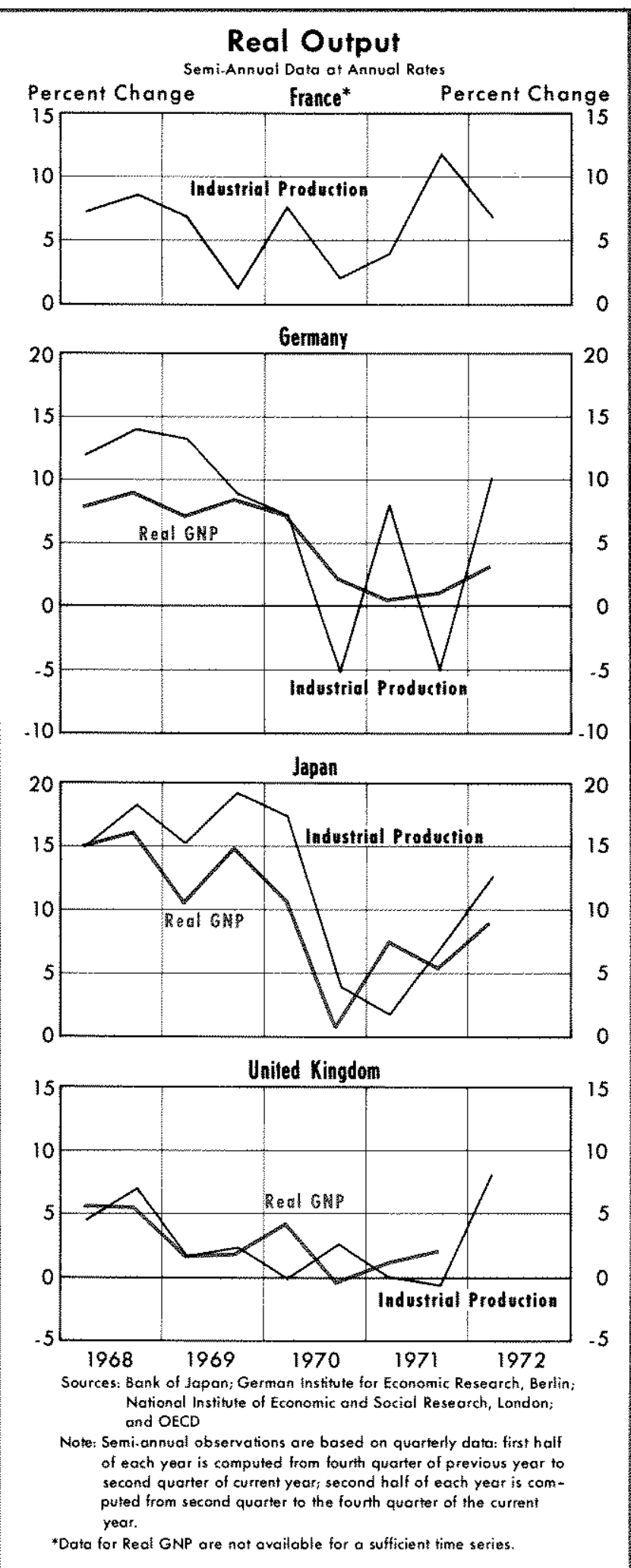

and real GNP. In each case real output is measured as percentage changes over a half-year period. Real GNP is not plotted in the case of France because current values of that series are not available. 
Both measures of real output demonstrate substantially the same cyclical pattem, with the exception of small differences in timing. These exceptions are due to (1) the differences in coverage of the two series and (2) errors in data collection. The industrial production series tends to be quite accurate in terms of its coverage of the industrial sector of the economy. However, it omits other sources of real output such as agriculture and government, which are captured in the real GNP series. On the other hand, development of a real GNP series in these countries is relatively recent; therefore, errors in data collection may be greater. Plotting both series provides a rough range within which one can judge the timing of the cyclical movements in real output.

For each country in this group, real output growth has displayed a systematic cyclical pattern which has followed, with a short lag, the pattern of money growth. In France a cyclical trough in money occurred in the first half of 1970 and a trough in industrial production followed in the second half of 1970. For Germany a cyclical trough in money was observed in the first half of 1970 while that in real output appears to have been in 1971. In the case of Japan the paths of real GNP growth and money growth were very similar, with the troughs in each series occurring in the second half of 1970 . The trough in industrial production occurred about one-half year later. Finally, a cyclical trough in money for the United Kingdom appeared in the first half of 1969 and a corresponding trough in real GNP came in the second half of 1970 ; the recovery of industrial production, however, did not occur until about one year later.

\section{Economic Explanation of Stagflation}

It is possible to explain the temporary, simultaneous occurrence of an acceleration in prices and a deceleration in output (stagflation) on the basis of the differential effects of monetary influences on prices and output. Past experience indicates that it takes a relatively long time period for monetary influences to have their full effect on prices. Thus the current acceleration in inflation among these countries is associated with the acceleration in the money stock over a period of at least three to four years. Since the relationship between money and real output is relatively short term, a temporary deceleration in money, even in a period of general acceleration, can lead to a temporary slowdown in the growth of real output. A companion article in this issue of the Review indicates that these same observations have been made for the United States in recent years.

\section{Conclusions}

This note has examined the basic contours of the economic performance of four industrial countries during recent years. It has been found that the otherwise confusing and conflicting currents of economic events (falling production and rising prices) in those countries is consistent with the following economic propositions:

1) The general trend of accelerating inflation is strongly related to the accelerating trend growth in the money stock.

2) Fluctuations in the rate of growth of money will be followed by, in the short run, similar fluctuations in the growth of real output.

It is therefore possible to have both rising prices and falling output for a year or two. The deceleration in the growth of real output which has occurred in each country can be explained by a temporary deceleration in the growth of the money stock. By the same token the most recent acceleration in the growth of real output in most of the countries considered is associated, with some lag, with the acceleration in the growth of the money stock. The rates of inflation that have prevailed in these countries can be attributed to accelerating trends in money growth.

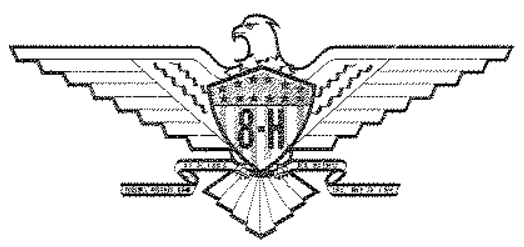

